\title{
Offensive and Defensive Marketing in Spatial Competition
}

Keywords: spatial competition; defensive marketing; offensive marketing; resource allocation; travel costs.

\author{
Guiomar Martín-Herrán \\ Dpto. Economía Aplicada (Matemáticas), \\ IMUVA, Universidad de Valladolid and GERAD, Spain and Montréal, Canada \\ E-Mail address: guiomar@eco.uva.es
}

Simon Pierre Sigué

Faculty of Business, Athabasca University

201-13220 St. Albert Trail

Edmonton, Alberta, Canada T5L 4W1

E-mail: simons@athabascau.ca

Tel.: 780-460-0340 


\title{
Offensive and Defensive Marketing in Spatial Competition
}

\begin{abstract}
While it is well-established that travel costs impact on customer preference toward local service providers, research about how this situation affects competitive marketing strategies remains sparse. This paper investigates, in a local market with two competing service providers, whether service providers should undertake defensive marketing, targeted at the nearest customers who typically prefer their offering for convenience and/or offensive marketing, directed to relatively remote customers who favor the rival as the closest alternative. We find that the service providers can exclusively undertake either defensive marketing or offensive marketing or combine the two in a full differentiated strategy at the equilibrium. We compare the outcomes of these three strategic options to identify the conditions under which they are worth implementing. Main findings suggest that service providers are better off undertaking offensive marketing alone when their rival's retaliatory offensive capacity is weak and customers incur small travel costs. Otherwise, service providers may exclusively undertake defensive marketing or combine it with offensive marketing when travel costs become significant. Also, service providers should not invest in any marketing activity when they have no market power, like in
\end{abstract}


the case of two adjacent outlets in a mall. Finally, the implications of these findings are discussed.

\section{INTRODUCTION}

Service providers in mature markets have the strategic choice of targeting their marketing activities at two basic segments, namely at their own customers and their rivals' customers, and to allocate their resources accordingly (see Berger and Bechwati 2001; Reinartz, Thomas, and Kumar 2005; Tsao 2013). Marketing activities directed at a firm's own customers are called defensive marketing or customer retention activities. Their main goals are generally to prevent customer churn and/or increase the consumption of current customers (Durvasula, Lysonski, and Mehta 2000; Erickson 1993). Conversely, marketing activities targeted at rivals' customers are called offensive marketing or customer acquisition activities in the customer relationship management (CRM) literature. They typically encourage brand switching and aim at expanding a firm's customer base (Durvasula, Lysonski, and Mehta 2000; Martín-Herrán, McQuitty, and Sigué 2012).

The importance of effective resource allocation to offensive and defensive marketing activities is well documented in the marketing and service literature (e.g., Blattberg and Deighton 1996; Fornell and Wenerfelt 1987; Fruchter and Sigué 2005; Pfeifer 2005, Reinartz, Thomas, and Kumar 2005; Voss and Voss 2008). Based on the widely accepted idea that, it is considerably cheaper to retain a customer than to attract a new one in various industries, the 
conventional wisdom is that priority should be given to defensive over offensive marketing activities to enhance profitability (Fruchter and Sigué 2009; Pfeifer 2005). However, a few analytical works have demonstrated that the cost differential between customer acquisition and retention should not be the only factor to consider for optimal resource allocation (e.g., MartínHerrán, McQuitty, and Sigué 2012; Musalem and Joshi 2009). As a consequence, there is increasingly a general agreement that the optimal allocation of marketing resources to customer acquisition and retention is contingent on the market conditions and the factors that affect competition in an industry (e.g., Bridges and Freytag 2009; Jørgensen and Sigué 2015; Tsao 2013; Voss and Voss 2008).

Despite this agreement, the allocation of marketing resources to offensive and defensive activities in the context of spatial competition, in various service sectors such as car washes, dry cleaners, banks, beauty salons, and fitness centers, has been overlooked in the current literature. Competition in service sectors is generally localized as consumers typically need physical contacts with service providers and prefer those that are closer to them (Chisholm and Norman 2012; Cleeren, Dekimpe, and Verboven 2006; Ho and Ishii 2011). Therefore, firms in service sectors compete not only on traditional marketing variables, but also relative to their location as shown in various spatial competition models (see Biscaia and Mota (2013) for a review). For instance, studying price competition among gasoline retailers in Singapore, Chan, Padmanabhan, and Seetharaman (2007) report that consumers are willing to travel up to a mile to save $\$ .03$ per liter. They also find that a gasoline retailer's market share is negatively influenced by consumer travel costs. Ho and Ishii (2011) also find in the banking sector that customer utility decreases with travel costs. Consequently, in the context of this research, we believe that if competitors are not located at the same place and customers are uniformly distributed, higher travel costs give 
each competitor a local monopoly power, which can reduce the need to invest in defensive marketing. Competitors can find it costly and less attractive to attack each other's local customer base beyond a certain distance within their trading or catchment areas (Dolega, Pavlis, and Singleton 2016, Huff 1964). As a matter of fact, Davis (2006) finds that a typical movie theater has a retail catchment or geographic market of a maximum of 15 miles radius. Conversely, when travel costs are small, consumers can easily move from one firm to another. There is an obvious incentive to strongly defend one's own customers and to attract those of the rivals. Thus, travel costs should be considered as a critical ingredient of any theory that attempts to explain resource allocation to offensive and defensive marketing when competition is localized, as observed in various retailing settings.

This paper proposes a resource allocation framework to offensive and defensive marketing that applies to competition between local service providers. We develop a Hotellingtype model where two firms localized at the two extremes of a line offer the same service. The two firms have captive markets due to their location and can invest in both offensive and defensive marketing to improve consumer valuation of their offerings, but also to retain captive customers (nearest customers) and attract those of the rival (remote customers). Similar to traditional Lanchester models, any attempt to acquire new customers beyond own market base is considered as an assault to the rival's customer base (Jørgensen and Zaccour 2004). Customers pay a travel cost per unit of distance travelled to purchase the service from either of the two firms, which benefit from their local monopoly power. Assuming exogenous prices, customers' preferences toward competitors exclusively depend on their location and the marketing activities undertaken by the two firms. Our research questions then are: 
1. Could the firms exclusively target either their own customer base or the rival's customer base, or could they simultaneously commit resources to both own and the rival's customer bases at the equilibrium?

2. What should the optimal equilibrium marketing strategies be if the two firms act so as to maximize their respective profits?

To answer these two questions, the two firms play a Nash game and determine their offensive and/or defensive marketing decisions simultaneously, taking those of the rival as given. The equilibrium outcomes are then compared to identify the conditions under which a firm either focuses exclusively on own customer base or the rival's or simultaneously targets these two market segments to maximize profits.

The remainder of this paper is organized as follows. Section 2 provides a brief review of previous works. Section 3 presents the model and describes the derivation of the three equilibrium solutions. Section 4 compares the three equilibrium solutions to identify the optimal resource allocation to offensive and defensive marketing. Section 5 describes the framework derived from the findings of this research. Finally, Section 6 concludes and discusses the implications and limits of this research. 


\section{LITERATURE REVIEW}

Several works have investigated the optimal allocation of resources to offensive and defensive marketing activities in the analytical marketing literature (e.g., Blattberg and Deighton 1996; Berger and Bechwati 2001; Erickson 1993; Jørgensen and Sigué 2015; Martín-Herrán, McQuitty, and Sigué 2012; Musalem and Joshi 2009; Reinartz, Thomas, and Kumar 2005; Tsao 2013). Our research shares more similarities with the works by Erickson (1993), Martín-Herrán, McQuitty, and Sigué (2012), and Musalem and Joshi (2009).

The first two extend traditional Lanchester models, which exclusively study offensive advertising (e.g., Erickson 1985; Jarrar, Martín-Herrán, and Zaccour 2004; Jørgensen and Zaccour 2004), to investigate dynamic competition in a duopoly market when the firms, regardless of their location, can invest in both offensive and defensive marketing. They both assume a mature market of a determined size as we do in this paper and describe how firms battle for market share over time. Using differential games, the findings of these works indicate how the firms can optimally invest in both offensive and defensive marketing as their market share evolves over time. For instance, Martín-Herrán, McQuitty, and Sigué (2012) report that, under certain conditions, investments in both offensive and defensive marketing may increase or decrease with a firm's market share, depending on factors such as the firms' competitive advantage/disadvantage in performing marketing activities, and the costs and effectiveness of the two types of marketing activities. The current paper differs from these previous works in several aspects. In particular, we study static competition between two firms that have relative local monopoly power due to customer travel costs. As a result, a firm's market base, in this case, does not necessary consist of people who have already purchased its service, but by people who would normally purchase from it as their nearest provider, all else being equal. In such a context, in 
addition of the firms' marketing activities, customers' preferences for the service providers also depend on their location.

On the other hand, Musalem and Joshi (2009) study how competitors should invest in individual customer acquisition and retention over two periods. Their findings support the view that a firm's optimal allocation of marketing resources to a customer depends on that customer's intrinsic preference toward competitors, its contribution margins for each competitor, and its responsiveness to competitors' acquisition and retention activities. In particular, a firm should heavily invest to attract the rival's moderately profitable customers, while its greatest retention efforts should be targeted at its moderately responsive customers. This paper differs from theirs in the level of analysis, the time horizon, and the strategic goal of the competitors. Musalem and Joshi (2009) study resource allocation to a single customer over two periods, while this research addresses a similar issue in a local market in which, consumers are uniformly distributed between two competitors. The strategic goal of the competitors, in this paper, is not whether or not to develop a lasting relationship with a customer given his/her characteristics, but to find an optimal allocation of marketing resources in a local market to maximize aggregate profits. As a result, our work assumes the key difference between customers is their location, which impacts on their travel costs to purchase from either competitor. This allows us to capture the idea that competitors battle to acquire some customers more than others, based particularly on their proximity/remoteness.

Finally, unlike any other previous work, this paper endogenously identifies the conditions under which, localized competitors exclusively use either defensive marketing targeted at their captive customers or offensive marketing targeted at the rival's customer base or combine simultaneously both to maximize their profits at the equilibrium. We therefore propose a 
comprehensive framework, which offers normative recommendations about which marketing resource allocation scheme to implement in a spatial competition. The following four factors are the building blocks of this framework: the travel cost, the strength of the retaliatory offensive marketing attack of the rival, the extent of cost difference between offensive and defensive marketing, and the relative effectiveness of offensive and defensive marketing. As we will demonstrate, each of these factors individually influence spending in offensive and defensive marketing activities, but some have more impact than others in some situations. 


\section{THE MODEL}

Consider a market with $n$ potential consumers in which two firms sell the same service.

Each Firm $i, i \in\{1,2\}$, can use offensive marketing $\left(O_{i}\right)$ to attract the rival's customers and defensive marketing $\left(D_{i}\right)$ to retain their own customers. Consumers can choose between the two firms each located at the end points 1 and 2 of a straight line (Hotelling 1929). The consumers are distributed uniformly along this line and incur travel costs at the rate of $t$ per unit of distance. The parameter $t$ captures competition, as higher values of $t$ means the two firms are differentiated. The consumers located at 1 derive a gross value $\mathrm{v}$ from purchasing the service from Firm 1 and $v-t$ from purchasing the service from Firm 2, given that the distance between the two firms is set to 1 . The two end points are ideal points where consumers will purchase the service without bearing any travel cost. The corresponding value of a purchase made at a distance $d$ is $v+f\left(O_{i}, D_{i}\right)-t d$, where $f\left(O_{i}, D_{i}\right)$ depends positively on $O_{i}$ and $D_{i}$. This specification captures the fact that a Firm $i$ 's investments, either in defensive or offensive marketing, contribute to improving consumer valuation of its offering. It also means that consumer perception of a brand, at any given moment, depends on its current investments in both offensive and defensive marketing and location.

Consumers purchase the offering of any given firm only if it gives them a positive surplus. Therefore, the marginal consumer located at $d \in[1,2]$ will be indifferent from buying either from Firm 1 or Firm 2 if $d$ meets the following condition:

$$
\begin{gathered}
v+f\left(O_{1}, D_{1}\right)-t d=v+f\left(O_{2}, D_{2}\right)-t(1-d), \text { and therefore, it is given by: } \\
d=\frac{t+f\left(O_{1}, D_{1}\right)-f\left(O_{2}, D_{2}\right)}{2 t} .
\end{gathered}
$$


Consumers located on the left side of $d$ naturally purchase from Firm 1, while those locate on the right side of $d$ purchase from Firm 2. Therefore, if we denote $x_{i}$ the market share or base of Firm $i$, we obtain $x_{1}=d$ and $x_{2}=1-d$. We then can express the market share of Firm $i$ as follows:

$$
x_{i}=\frac{t+f\left(O_{i}, D_{i}\right)-f\left(O_{j}, D_{j}\right)}{2 t}, i, j=1,2, \quad i \neq j .
$$

From the above expression, it is obvious that the two firms have identical market share either when they do not invest in both offensive and defensive marketing or their efforts to locally improve consumer valuation of their respective offerings mutually nullify each other.

The following general demand function for Firm $i$ is adopted:

$$
q_{i}=n x_{i} g_{i}\left(O_{j}, D_{i}\right)+n x_{j} l_{i}\left(O_{i}\right), \quad i, j=1,2, i \neq j,
$$

where $g_{i}\left(O_{j}, D_{i}\right)$ depends positively on $D_{i}$ and negatively on $O_{j}$, and $l_{i}\left(O_{i}\right)$ depends positively on $O_{i}$. This demand function captures the idea in Erickson (1993) that all of a firm's customers are exposed to the rival's offensive marketing attack and therefore need to be defended. This is because, while customers may naturally prefer a service provider to another based on location, the marketing activities of the two firms affect their appeal to all customers in the market. Each firm can therefore control its demand by investing in both offensive and defensive marketing targeted at the rival's customer base and their own customer base, respectively, as shown in the second and first components of the demand function. Because a customer can only buy one unit of the product, the total demand $\left(q_{1}+q_{2}\right)$ for the two firms cannot exceed the number of potential customers, $n$.

Various specifications are possible for the functions $f\left(O_{i}, D_{i}\right), g_{i}\left(O_{j}, D_{i}\right)$ and $l_{i}\left(O_{i}\right)$. We choose the followings: 


$$
f\left(O_{i}, D_{i}\right)=\sqrt{O_{i}}+\sqrt{D_{i}}, \quad g_{i}\left(O_{j}, D_{i}\right)=-\delta \sqrt{O_{j}}+\sqrt{D_{i}}, \quad l_{i}\left(O_{i}\right)=\theta \sqrt{O_{i}},
$$

where the non-negative parameters $\theta$ and $\delta$ denote the direct effect of the competitors' offensive marketing on the demand functions. These concave functions are used to represent decreasing returns on investments in offensive and defensive marketing (e.g., Karray 2013). We normalize the direct effect of a firm's defensive marketing on its own demand to 1 to be able to study situations where the direct effects of both offensive and defensive marketing on demand either differ or are equal. Our specification also assumes that the two types of marketing activities contribute equally to consumer valuation and their individual contributions are set to 1 . This implies that the major difference between the two types of marketing activities is in their abilities to attract the rival's customers or to retain those in own market base.

An elegant representation of the resulting demand functions is given by:

$$
q_{i}=n x_{i} \sqrt{D_{i}}+n x_{j} \theta \sqrt{O_{i}}-n x_{i} \delta \sqrt{O_{j}}, \quad i, j=1,2, i \neq j
$$

This representation helps to visualize the demand functions taking the market share $x_{i}$,

$i \in\{1,2\}$, as given. One has to remember however that the market share is derived from consumers' utility, which is a function of the transportation cost $t$ and the two firms' offensive and defensive marketing. Therefore the demand for each firm depends on complex interactions between the two firms' offensive and defensive marketing, the travel cost, and the number of potential consumers in the market.

Let denote by $c \in[0,1]$ the unit cost of the defensive marketing of each of the two firms. We normalize the unit cost of offensive marketing to 1 to account for the widely accepted idea in the marketing literature that it costs more to acquire new customers than to keep current customers.

The profit function of Firm $i$ is given by: 


$$
\pi_{i}=r q_{i}-O_{i}-c D_{i}, \quad i, j=1,2,
$$

where $r$ denotes the identical margin of the two firms. Due to the symmetric structure of the model we focus on symmetric equilibria. The demand $(q)$ and profit $(\pi)$ for each firm when they both invest identically in offensive and defensive marketing, i.e., $O_{1}=O_{2}=O$ and $D_{1}=D_{2}=D$ are as follows:

$$
\begin{aligned}
& q=\frac{1}{2} n(\sqrt{D}+(\theta-\delta) \sqrt{O}) \\
& \pi=\frac{1}{2}[n r(\sqrt{D}+(\theta-\delta) \sqrt{O})-2(O+c D)] .
\end{aligned}
$$

Given the structure of our demand functions, it is easy to see that the two firms get zero demands and profits if they do not carry out any marketing activities. This is obviously a simplification. However, it helps to focus on the impact of both offensive and defensive marketing activities on competing firms' profits, which is the distinctive contribution of this research. An alternative specification with positive demands when offensive and defensive marketing activities are set to zero could easily be considered by adding a constant term in the demand function. This would mean whether or not the firms undertake offensive and defensive marketing, they maintain a minimum level of sales due to their location and, more likely, other activities exogenous to our model. Considering a Nash game between the two competitors, we characterize the equilibrium marketing strategies in the scenarios where offensive and defensive marketing are undertaken together and separately.

\section{Offensive-Defensive Marketing Equilibrium}


The offensive-defensive marketing (ODM) equilibrium characterizes the strategies and payoffs of the two firms when they both find it optimal to simultaneously invest in offensive and defensive marketing. This equilibrium is described in Proposition 1 below.

Proposition 1: When the two firms compete using a combination of offensive and defensive marketing, their equilibrium strategies, demands, and profits are as follows:

$$
\begin{aligned}
& O^{O D M}=\left(\frac{n r(n r(1-\theta)+4 c t \theta}{4(c(n r(\delta+\theta)+4 t)-n r)}\right)^{2}, \\
& D^{O D M}=\left(\frac{n r(n r(1-\theta)(\delta+\theta)+4 t)}{4(c(n r(\delta+\theta)+4 t)-n r)}\right)^{2}, \\
& q^{O D M}=\frac{n^{2} r(n r(1-\theta) \theta+2 t(1+c(\theta-\delta) \theta))}{16(c(n r(\delta+\theta)+4 t)-n r)}, \\
& \pi^{O D M}=n^{2} r^{2} \frac{N u m \pi^{O D M}}{(4(c(n r(\delta+\theta)+4 t)-n r))^{2}}
\end{aligned}
$$

where:

$N u m \pi^{O D M}=n r(n r(1-\theta) \theta+2 t(1+c \theta(\theta-\delta)))(4 c t-n r(1-c(\theta+\delta)))-(n r(1-\theta)+4 c t \theta)^{2}$

$-c(4 t+n r(1-\theta)(\delta+\theta))^{2}$.

Proof: See the Appendix.

Proposition 1 shows that the game outcomes in this scenario depend on all game parameters, including the number of potential consumers $(n)$, the unit margin $(r)$, the travel cost $(\mathrm{t})$, the unit cost of defensive marketing $(c)$, and the effectiveness of a firm's own $(\theta)$ and rival's offensive marketing $(\delta)$. Some conditions need to be imposed on these parameters to obtain nonnegative profits, simultaneous positive offensive and defensive marketing, and positive demands as well as to ensure that the sales of the two firms do not exceed the number of potential consumers. We look for non-negative profits to ensure that the two firms can at least break-even. 
Simultaneous positive offensive and defensive marketing decisions are needed for an interior solution. Otherwise, corner solutions where only one of the two types of marketing is conducted are considered. Although we are analytically able to identify general closed-form expressions for these conditions, they are not reported in the text or in the appendix. However, they are available from the authors upon request and are used for numerical simulations to further inform the impact of some parameters on the game outcomes.

\section{Exclusive Defensive Marketing Equilibrium}

In this subsection we study the scenario where the two firms only undertake defensive marketing at the equilibrium. The following proposition summarizes our findings.

Proposition 2: If $(n r \leq 2 c$ and $t \geq n r /(2 c))$ or $(2 c<n r \leq 4 c$ and $t \geq n r /(4 c-n r)$ ), the exclusive defensive marketing (EDM) equilibrium does exist. The equilibrium game outcomes are as follows:

$$
\begin{aligned}
D^{E D M} & =\frac{n r t}{4 c t-n r}, \\
q^{E D M} & =\frac{n^{2} r t}{2(4 c t-n r)}, \\
\pi^{E D M} & =\frac{n^{2} r^{2} t(2 c t-n r)}{2(4 c t-n r)^{2}} .
\end{aligned}
$$

Proof: See the Appendix.

The first condition of the existence of the EDM equilibrium in Proposition 2 is more likely to be verified, everything else being equal, when both the travel cost $(t)$ and the unit cost of defensive marketing $(c)$ are large and both the number of potential consumers $(n)$ and the unit margin $(r)$ are small. A large unit cost of defensive marketing means that the cost differential 
between offensive and defensive marketing is relatively small. Larger travel costs give local monopoly power to each firm, which reduces its vulnerability to the rival's offensive marketing attack. Finally, the potential income that the two firms can make is limited when either the number of potential consumers or the unit margin is small. The second condition also involves the parameters $t, c, n$, and $r$. It requires a higher travel cost, but this time with a higher relative potential income compared to the unit cost of defensive marketing, which should not be extremely large.

The equilibrium defensive marketing strategies and demands in Proposition 2 depend positively on the number of potential consumers and the unit margin and negatively on the travel cost and the cost of defensive marketing. Therefore, differentiated competitors invest less in defensive advertising as they do not see the need to enhance the valuation of their offerings to customers in the absence of the rival's attack. As expected, the two firms invest less in defensive marketing when their defensive marketing unit cost increases.

The two firms' profits decrease as the travel cost increases. However, the impacts of the variations of other model parameters on profits are not straightforward. They all depend on the relative values of the remaining parameters with respect to the travel cost given the feasibility conditions identified in Proposition 2. Under the first feasibility condition, the profit can either increase or decrease with the cost of defensive marketing depending whether the travel cost is higher or lower than an identified threshold, which depends on the return a firm obtains by defending a individual customer and the total number of customers in the market. With higher travel costs, the two firms invest less in defensive marketing as its unit cost goes up and earn more profits. On the other hand, with lower travel costs, the intensity of local competition increases, each firm defends its customer base more, especially when the unit cost of defensive 
marketing gets smaller. As a result, the profits of the two firms decrease. This is due to the fact that, although defensive marketing enhances consumer valuation of the firm's offering, its market expansion capacity is limited as neither of the two firms have the capacity to directly appeal to the market base of the competitor. On the other hand, under the second feasibility condition, the two firms' profits always increase as the number of potential consumers, the unit margin, and the cost of defensive marketing increase.

\section{Exclusive Offensive Marketing Equilibrium}

We now study the scenario where the two firms exclusively play offensive marketing at the equilibrium. Proposition 3 presents the equilibrium outcomes and identifies their feasibility conditions.

Proposition 3: Everything else being equal, the two firms exclusively undertake offensive marketing at the equilibrium if and only if a firm's own offensive marketing is more effective than the rival's retaliatory offensive marketing and conditions in (16) are satisfied. The outcomes of the exclusive offensive marketing (EOM) equilibrium are as follows:

$$
\begin{aligned}
& O^{E O M}=\frac{n r t \theta}{4 t+n r(\delta+\theta)}, \\
& q^{E O M}=\frac{n^{2} r t \theta(\theta-\delta)}{2(4 t+n r(\delta+\theta))}, \\
& \pi^{E O M}=\frac{n^{2} r^{2} t \theta\left(2 t(\theta-2 \delta)+n r\left(\theta^{2}-\delta^{2}\right)\right)}{4(2 t+n r \theta)^{2}} .
\end{aligned}
$$

Proof: See the Appendix. 
Proposition 3 suggests that, the EOM equilibrium is exclusively played in a context where an assault on the rival's customer base contributes to an increase in demand that is greater than the loss incurred when the firm's own customer base is attacked. Therefore, defending their own consumers becomes less a priority than attracting new consumers from the rival.

The equilibrium offensive marketing strategies and the demands in Proposition 3 increase with the unit margin, the number of potential consumers, the effectiveness of their own offensive marketing, and the travel cost and decrease with the effectiveness of the rival's offensive marketing. Also, as expected, the profits increase with the unit margin, the number of potential consumers, the effectiveness of the firm's own offensive marketing and decrease with the effectiveness of the rival's offensive marketing. Surprisingly, the profits may increase or decrease with the travel cost depending on its relative value with respect to the remaining model parameters. 


\section{CHOOSING A MARKETING BATTLE}

This section numerically investigates the conditions under which the two competitors may find it optimal to implement any of the three equilibria presented above. We compare the firms' profits under the three equilibria for certain values of the parameters. As in Shaffer and Zettelmeyer (2009), we set the number of consumers $(n)$ to 1 . The unit margin $(r)$ is not a key ingredient of the theory developed in this paper. It is normalized to 1 . We vary the parameters $t$ and $\theta$ in the following ranges: $t \in(0,5], \theta \in[0,1]$, and $\theta \in[1,2]$, given $c \in\{0.1,0.25,0.5,0.75,0.9\}$. Because the effectiveness of defensive advertising is normalized to 1 , analyzing these equilibria where $\theta \in[0,1]$ and $\theta \in[1,2]$ allows us to study two scenarios where offensive marketing is less and more effective, respectively, in increasing sales than defensive marketing. In the next three subsections, we discuss the feasibility conditions of the three equilibria and their adoption for $\delta=\theta, \delta=1.5 \theta$, and $\delta=0.5 \theta$, which correspond, respectively, to the scenarios where an offensive marketing attack is met with an identical, a stronger, and a weaker retaliatory offensive marketing response from the rival.

\section{Identical Responses to Attacks}

The two firms know that attacking the rival's consumer base will generate a response of the same strength, i.e., $\delta=\theta$. Under this assumption, the feasibility conditions of the three equilibria for $c=0.5$ are illustrated in Figure 1a for $\theta \in[0,1]$ and Figure $1 \mathrm{~b}$ for $\theta \in[1,2]$.

(Insert Figures $1 \mathrm{a}$ and $1 \mathrm{~b}$ about here) 
Both the ODM and EDM equilibria are feasible in some areas of the parameter space. The qualitative findings of the above figures do not change with higher values of $c$. However, the area in which none of the three equilibria is feasible becomes smaller as $c$ increases.

For $c=0.25$, only the ODM equilibrium is feasible when $\theta \in[1,2]$, as we illustrate in Figure 2 below:

(Insert Figure 2 about here)

All three equilibria are unfeasible for $c=0.1$.

This numerical analysis confirms a finding in Proposition 3 that the EOM equilibrium is automatically unfeasible when $\delta \geq \theta$. Therefore, it is not a surprise that in this case the two firms can only play the EDM and ODM equilibria. The exclusive focus on offensive marketing activities in such a context leads to a marketing war that dramatically increases marketing expenditures and ruins the profitability of the two firms.

In support of Proposition 2, the EDM equilibrium is always feasible when the travel cost is relatively high or very high and the cost of defensive marketing is relatively high, regardless of whether or not a firm's offensive marketing is less effective $(\theta \in[0,1])$ or more effective $(\theta \in[1,2])$ than its defensive marketing. Conversely, the EDM equilibrium is not sustainable when the defensive marketing cost is small $(c \in\{0.1,0.25\})$ for any value of the travel cost. Thus, the combination of a higher travel cost and a larger defensive marketing cost attenuates the vulnerability of the two firms and reduces the propensity to overspend in defensive marketing activities.

The feasibility of the ODM equilibrium depends on the travel cost, $t$, the effectiveness of offensive marketing, $\theta$, and the cost of defensive marketing, $c$. In particular, the ODM 
equilibrium cannot be played for small values of $t$ and for very large values $\theta$, when the cost of defensive marketing is large. Conversely, it is the unique feasible equilibrium when the travel cost is high, the effectiveness of offensive marketing is high, and the cost of defensive marketing is relatively small (see Figure 2).

Given the above feasibility conditions, the comparisons of the two firms' profits under the EDM and ODM equilibria are illustrated in Figure $3 a$ for $\theta \in[0,1]$ and Figure $3 b \quad \theta \in[1,2]$, and $c=0.5$.

(Insert Figures $3 \mathrm{a}$ and $3 \mathrm{~b}$ about here)

All else being equal, the selection of the equilibrium to be implemented depends on the cost of defensive marketing, the travel cost, and the effectiveness of offensive marketing. As shown in Figure 3, in most areas of the feasible parameter space, the two firms play the EDM equilibrium. The ODM equilibrium is preferred for $\theta \in(0.4,1.6)$ when the travel cost is relatively small or approximately equal to 1 . The analysis with higher values of $c$ gives similar qualitative findings. In addition, the ODM equilibrium is also adopted as the unique feasible equilibrium for $c=0.25$, as illustrated in Figure 2 .

\section{Stronger Responses to Attacks}

We repeat the analysis conducted in the subsection above. However, this time we consider that a firm's own offensive marketing $(\theta)$ is less effective than that of the rival $(\delta)$ and set, $\delta=1.5 \theta$. We first identify the feasibility conditions of the three equilibria and then compare their profits. The feasibility conditions of the three equilibria for $c=0.5$ are illustrated in Figure $4 \mathrm{a}$ for $\theta \in[0,1]$ and Figure $4 b \theta \in[1,2]$. 
(Insert Figures $4 \mathrm{a}$ and $4 \mathrm{~b}$ about here)

Similar analyses were conducted for various values of $c$. We found that for larger and smaller values of $c$, some findings were different from those presented in the above figures. Specifically, for $\theta \in[1,2]$ and $c=0.9$ or $c=0.75$, only the EDM equilibrium is feasible; while for $c=0.1$, none of the three equilibria is feasible for both $\theta \in[0,1]$ and $\theta \in[1,2]$. The qualitative findings in Figure 4 remain unchanged when $c=0.25$.

(Insert Figures 5a and 5b about here)

As expected from Proposition 3, the EOM equilibrium is always unfeasible in this scenario. The EDM and ODM equilibria are feasible in some areas of the parameter space. Specifically, the EDM equilibrium is feasible when the travel cost is above a certain threshold and the defensive marketing cost is relatively high or very high, regardless of whether a firm's own offensive marketing is more effective or less effective than its defensive marketing. The ODM is feasible when a firm's own offensive marketing effectiveness is not very superior to the defensive marketing effectiveness, the travel cost is above a certain threshold, and the cost of defensive marketing is relatively high or very high. This equilibrium is also feasible when the cost of defensive marketing is relatively small, the travel cost is high, and the effectiveness offensive marketing $(\theta)$ is approximately between 0.9 and 1.6 (Figure 5).

We perform the comparisons of the profits under the EDM and ODM equilibria in the common feasible domain. The findings for $c=0.5$ are illustrated in Figures $6 \mathrm{a}$ and $6 \mathrm{~b}$. 
(Insert Figures $6 \mathrm{a}$ and $6 \mathrm{~b}$ about here)

In Figure 6, the EDM equilibrium is played in most areas in the parameter space either because it is the unique feasible equilibrium or because it provides more profits to the two competitors. The ODM equilibrium is played in a smaller area where offensive marketing is as effective as defensive marketing or either one is lightly more effective than the other, the cost of defensive marketing is large, and the travel cost is relatively small. This area gets smaller as the cost of defensive marketing increases. The ODM equilibrium is also adopted as the unique feasible equilibrium when the cost of defensive marketing is relatively small as illustrated in Figure 5.

\section{Weaker Responses to Attacks}

We consider in this subsection that a firm's own offensive marketing is more effective than that of the rival and set, $\delta=0.5 \theta$. Again, we first identify the feasibility conditions of the three equilibria and then compare their profits. The feasibility conditions of the three equilibria for $c=0.5$ are illustrated in Figure $7 \mathrm{a}$ for $\theta \in[0,1]$ and Figure $7 \mathrm{~b} \theta \in[1,2]$.

(Insert Figures $7 \mathrm{a}$ and $7 \mathrm{~b}$ about here)

Figure 7 shows that all three equilibria are feasible in this scenario. Specifically, based on Proposition 3, the EOM equilibrium can be played. As in the previous scenarios, the EDM equilibrium can be played for travel costs above an identified threshold and for any value of the effectiveness of offensive marketing if the cost of defensive marketing is large enough. The 
feasibility condition of the EDM equilibrium also applies to the ODM equilibrium, with the exception that this equilibrium is not feasible when the travel cost is close to the threshold and the effectiveness of offensive marketing is either very small or very large. Repeating the same analysis with different values of $\mathrm{c}$, we found that the EDM and ODM equilibria are unfeasible for $c \in\{0.1,0.25\}$, while the area where these two equilibria are feasible increases as $c$ takes larger values. As a result, the area where only the EOM is feasible becomes smaller.

In Figure 8, we illustrate the comparisons of the profits of the three equilibria for $c=0.5$, given the feasibility conditions discussed above.

(Insert Figures $8 \mathrm{a}$ and $8 \mathrm{~b}$ about here)

The findings in Figure 8 support the view that, when $\mathrm{c}=0.5$, either the EDM equilibrium or the ODM equilibrium can be implemented if the travel cost is above the threshold value that ensures the feasibility of at least one of these two equilibria. Below this threshold value of the travel cost, only the EOM can be implemented as the unique equilibrium. Increasing the values of $c$ gives similar findings, with an additional component that the EDM equilibria is only implemented for smaller values of the effectiveness of offensive marketing. Conversely, for smaller values of $c$ (i.e., $c \in\{0.1,0.25\}$ ), the EOM is again implemented as the unique feasible equilibrium. 


\section{DISCUSSION}

This work provides a general framework that can be used to determine the type of marketing battle that two competing firms can locally undertake if they act so as to maximize their respective profits. This framework is built on the following four factors: the strength of the retaliatory offensive marketing attack of the rival, the travel cost, the cost differential between offensive and defensive marketing, and the relative effectiveness of offensive and defensive marketing. Table 1 provides an illustration of this framework using the findings of our numerical analysis.

(Insert Table 1 about here)

Table 1 shows that the effects of the above four factors are combined to determine the firms' equilibrium marketing strategies. We describe the individual influence of each of these factors below.

The intensity of the retaliatory attack is defined as the level of offensive marketing response of a firm to its rival's offensive marketing assault (Steenkamp et al. 2005). In Table 1, we consider that when a firm initiates an offensive marketing attack, it can expect its rival to react either with an identical offensive marketing response or with a stronger or weaker offensive marketing response. Our framework indicates that competing firms should avoid playing the EOM equilibrium in situations where any firm's offensive marketing effectiveness can be readily matched or exceeded by the rival's offensive marketing. Therefore in situations where an offensive marketing attack generates an identical or stronger retaliatory reaction from the rival, the two firms have three possibilities. Depending on other parameters, they can either do or refrain from doing the two types of marketing activities simultaneously or focus exclusively on 
defensive marketing to protect their respective customer bases. On the other hand, when the competitive retaliatory attack of the rival is weak or diffident, the two firms can engage in an offensive marketing war at any time, but may prefer, in some situations, to play either the EDM or the ODM equilibrium to earn more profits.

The second key factor of our framework is the travel cost. A larger travel cost implies that customers are more dependent on their nearest firm. The two firms have relative local market power as their offerings are significantly differentiated. Our framework supports the view that when the two offerings are less differentiated, the two firms could either avoid doing any of the two types of marketing activities or exclusively undertake offensive marketing. Conversely, when the two offerings are significantly differentiated, depending on the other parameters, the firms have four strategic options: refrain from doing any marketing activity, do either offensive or defensive marketing, or do both offensive and defensive marketing simultaneously.

The extent of cost difference between offensive and defensive marketing is the third factor of the framework. After normalizing the unit cost of offensive marketing to 1 , we consider the unit cost of defensive marketing as the percentage of expenditure necessary to retain a current customer with respect to what is required to attract a new customer. This third factor comes to play only when the travel cost is large enough. In this context, the two firms should find it optimal either not to undertake any marketing activity or to play the EOM equilibrium when defending captive customer only costs $10 \%$ of the investment required to attract a new customer. When this percentage reaches $25 \%$, the two firms can play either the ODM or EOM equilibrium. For percentages of $50 \%$ or more, only the EDM and ODM equilibrium can be implemented, although the EOM is feasible. 
The last factor to consider in our framework is the relative importance of offensive and defensive marketing in demands. In particular, in our framework, when $\theta \in[0,1](\theta \in[1,2])$, offensive marketing is less (more) effective than defensive marketing. Everything else being equal, firms are expected to give priority to the type of marketing activities that impact their sales most (Martín-Herrán et al. 2012). From the findings of our numerical analysis, this factor plays a game changing role in some specific cases. For instance, in Table 1, with identical responses to attacks, $c=0.25$, and a transportation cost above an identified threshold, the ODM equilibrium can be played for $\theta \in[1,2]$, while it is automatically unfeasible for $\theta \in[0,1]$. Also, all else being equal, in a situation of stronger retaliatory offensive marketing responses, relatively large transportation costs, and $c=0.75$ or $c=0.9$, both the EDM and ODM equilibrium can be implemented for $\theta \in[0,1]$, while only the EDM equilibrium is feasible for $\theta \in[1,2]$. 


\section{CONCLUSION AND IMPLICATIONS}

This paper has investigated how two competing service providers operating in a local market (e.g., dry cleaners, fitness centers, banks, and beauty salons) can allocate their resources to offensive and defensive marketing in the context where customers factor travel costs in their patronage decisions. The main findings of this research are summarized in Table 1. This conclusion focuses therefore on presenting the managerial and theoretical implications of our findings. A few assumptions, on which these findings are based, will also be discussed for future extensions.

From a managerial perspective, these findings suggest that in contexts where customers typically travel to providers to access services, competitors can use geographic segmentation to improve the effectiveness of their marketing programs. Under certain conditions, local service competitors have the following three strategic alternatives. First, they can exclusively target the nearest customers who are normally expect to buy from them based solely on location and develop defensive marketing programs that prevent these captive customers from considering alternative offerings from distant competitors. Such defensive marketing programs may, among others, highlight the convenience offered to nearest customers as the main competitive advantage. Second, service providers can also exclusively target relatively remote customers, in the trading area, who would normally buy from the rival given their location. In this case, they should offer attractive offensive marketing programs that downplay convenience and emphasize other benefits able to give them a competitive edge over the rival. Third, local service firms can simultaneously target nearest and relatively remote customers with marketing programs that competitively respond to the needs of these two market segments. Among others, the first and third strategic alternatives are not feasible (should therefore be avoided) when competitors have 
no local market power, while the second alternative can only be considered when the rival's retaliatory offensive marketing is weak.

The choice to implement any of these three equilibria depends on several factors, including the travel cost, the strength of the retaliatory offensive marketing attack of the rival, the extent of cost difference between offensive and defensive marketing, and the relative effectiveness of offensive and defensive marketing. For instance, targeting exclusively the rival's market base is the best strategy either when customer can easily move from one firm to another or the relative cost to protect own customer base is very small and the rival's offensive marketing retaliatory capacity is weak. Otherwise, the competitors find it optimal to either target exclusively their own customer bases or target the two market segments in some areas of the parameter space, while in other areas, competitors avoid undertaking any marketing activity. Situations where neither defensive nor offensive marketing is conducted mostly arise when travel costs are very small and the rival's offensive marketing retaliatory capacity is at least of the same strength. This is because there is no real competitive advantage due to location, as in the case of two adjacent competitors in a shopping center, and engaging to a marketing battle is detrimental to the competitors' profits: Any offensive gain from the rival's market base results to a bigger loss in own market base. In any case, while further empirical research is required to validate the use of such marketing strategies, increasingly, retailers request postal codes to customers at the time of purchase to better identify the geographical distribution of their customers. This information can help for the implementation of the type of marketing strategies we prescribe in this paper.

From a theoretical perspective, this paper confirms a finding in Martín-Herrán, McQuitty (2012) and Musalem and Joshi (2009) that relying exclusively on cost differential between 
offensive and defensive marketing activities, as claimed by the conventional wisdom, can lead to misallocation of resources across marketing activities in spatial competition. In fact, the costs of local marketing activities are generally associated with the use of local media (e.g., radio, newspapers). Because, the same local media are more likely to be used for the two market segments, one would normally expect local defensive and offensive marketing activities to have similar cost structures. Even in such a case, local service providers, with local market power, would exclusively focus on defending their market base. The only exception that leads to combining both offensive and defensive marketing at the equilibrium is when offensive marketing is more effective than defensive marketing and the retaliatory capacity of the rival is weak.

Lastly, while our research focuses on spatial competition, our findings can be generalized to competition in situations where physical location does not matter. This is possible by extending the concept of travel cost, central to our analysis, to switching cost as in Musalem and Joshi (2009) to a change of intrinsic preferences toward competitors. As a matter of fact, in various subscription services such as satellite television, cable, Internet, and newspapers the challenge for consumers is not the effective distance travelled to reach a service provider, but the psychological, economic, emotional, and affective attachments to services that create switching costs and make it difficult to move from one service provider to another (Chui et al. 2005). Companies are increasingly aware of this new reality and try to find alternative coercive ways to limit customer mobility. For instance, some cell phone providers such as Verizon, Sprint, TMobile, and AT\&T actively try to lock in customers by charging prohibitive cancellation fees (Fruchter and Sigué 2013). These switching costs are comparable to travel costs and help to secure relative captive markets for each competitor. In such a case, however, service providers 
do not need to base their marketing strategies exclusively on geographic segmentation, as discussed earlier, but on customer broad intrinsic preferences toward each firm, as in Musalem and Joshi (2009), that may lead to any relevant segmentation basis.

We have developed a parsimonious model to study a very complex phenomenon and derive meaningful insights. This was only possible by making some simplifying assumptions that may limit the generalizability of some of our findings. Future research could explore the possibility of relaxing these assumptions. For instance, we have assumed that the two service providers are symmetric. However, there are business situations where the competitors have different market powers or the effectiveness of their marketing activities differ. In such a context, the two firms may not undertake the same marketing activities at the equilibrium as we have in this paper. As a matter of fact, Steenkamp et al. (2005) shows that the competitive reactions to advertising and promotion attacks depend, among others, on the market power of the competitors.

Also, another key assumption of this research is that both offensive and defensive marketing positively influence consumer preference, while there is evidence that offensive marketing directed to the rival's customers that offer exclusive benefits to this segment may negatively affect core customers and increase consumer churn. A different model specification is required to capture this phenomenon known as the spoiling effect of customer acquisition on retention (e.g., Dong, Yao, and Cui 2011).

Finally, we have studied the case of autonomous local service providers who are able to sale directly to customers and independently make their local marketing decisions. The findings of our research may not therefore apply to local service providers who act as intermediaries in longer distribution channels or belong to larger network organizations such as franchise systems. 
It is now well established that marketing decisions in such settings are not only influenced by horizontal interactions, as we do, but are also affected by vertical interactions with other partners overlooked in this research (Chennamaneni, Desiraju, and Krishnamoorthy 2017). 


\section{APPENDIX}

\section{Proof of Proposition 1}

Firm's $i$ objective function after the expression of the demand function has been replaced reads:

$$
\pi_{i}=\frac{1}{2 t}\left[\begin{array}{l}
-2 t\left(O_{i}+c D_{i}\right)+r\left(n\left(\sqrt{O_{i}}-\sqrt{O_{j}}+\sqrt{D_{i}}-\sqrt{D_{j}}+t\right)\left(\sqrt{D_{i}}-\delta \sqrt{O_{j}}\right)+\right. \\
\left.n \sqrt{O_{i}}\left(\sqrt{O_{j}}-\sqrt{O_{i}}-\sqrt{D_{i}}+\sqrt{D_{j}}+t\right) \theta\right)
\end{array}\right], i, j=1,2, i \neq j
$$

The derivative with respect to $O_{i}$ and $D_{i}$ are:

$$
\begin{gathered}
\frac{1}{4 t \sqrt{O_{i}}}\left(-2(2 t+n r \theta) \sqrt{O_{i}}+n r\left((1-\theta) \sqrt{D_{i}}+\theta\left(\sqrt{D_{j}}+t\right)+(\theta-\delta) \sqrt{O_{j}}\right)\right), \\
\frac{1}{4 t \sqrt{D_{i}}}\left(2(2 n r-2 c t) \sqrt{D_{i}}-n r\left(\sqrt{D_{j}}-t+\sqrt{O_{j}}(1+\delta)-(1-\theta) \sqrt{O_{i}}\right)\right), \quad i, j=1,2, i \neq j .
\end{gathered}
$$

Equating the above expressions to zero, we get the first-order optimality condition for an interior equilibrium and solving for a symmetric solution (1) and (2) can be easily obtained. Replacing these last expressions in the demand and the firm's profits (3) and (4) are derived.

The second-order concavity conditions ensuring an interior maximum for the symmetric solution $(\mathrm{O}, \mathrm{D})$ read:

$$
\begin{aligned}
& \sqrt{D}+t \theta+(\theta-\delta) \sqrt{O}>0, \\
& D-((\theta-\delta) \sqrt{O}-t \theta)((\theta+\delta) \sqrt{O}-t)+\left(t(1-\theta)+\left(1+\theta^{2}\right)(\sqrt{O}) \sqrt{D}<0 .\right.
\end{aligned}
$$

\section{Proof of Proposition 2}

Replacing $O_{i}=0$ in (12) and equating to zero, $D^{E D M}$ in (5) is obtained. $D^{E D M}$ is positive if and only if $t>n r /(4 c)$. 
The optimal demand and profits in (6) and (7) can be easily obtained by substituting the expression of $D^{E D M}$. Therefore, if $t>n r /(2 c)$, then $D^{E D M}, q^{E D M}$ are positive and $\pi^{E D M}$ is greater or equal to zero. Note that $n r /(2 c)$ increases with $n$ and $r$, and decreases with $c$.

The condition on the total demand $q_{1}+q_{2} \leq n$, taking into account $q^{E D M}$ reads: $(4 c-n r) t \geq n r$. This last condition is only feasible if $4 c-n r>0$, and if this is the case, it can be rewritten as: $t \geq n r /(4 c-n r)$. Note that $n r /(4 c-n r)$ increases with $n$ and $r$, and decreases with $c$.

It can be easily checked that $n r /(4 c-n r) \geq n r /(2 c)$ if and only if $n r \leq 2 c$. Therefore, the corner solution $\left(\mathrm{O}=0, D^{E D M}\right)$ requires condition $(n r \leq 2 c$ and $t \geq n r /(2 c))$ or condition $(2 c<n r<4 c$ and $t \geq n r /(4 c-n r))$ in order to be feasible.

\section{Proof of Proposition 3}

Replacing $D_{i}=0$ in (11) and equating to zero, $O^{E O M}$ in (8) is obtained. The optimal demand and profits in (9) and (10) can be easily obtained substituting the expression of $O^{E O M}$.

If $\delta=\theta$, replacing in (9) and (10) one gets that the optimal demand is null and the optimal profits are negative. Therefore, this corner solution $\left(O^{E O M}, \mathrm{D}=0\right)$ is unfeasible when $\delta=\theta$.

From (9) and (10) the following conditions can be easily derived:

$$
\begin{aligned}
& q^{E O M}>0 \text { if and only if } \theta>\delta, \\
& { }_{\pi}^{E O M} \geq 0 \text { if and only if } 2 t(\theta-2 \delta)+n r\left(\theta^{2}-\delta^{2}\right) \geq 0 .
\end{aligned}
$$

Both conditions are satisfied simultaneously in the following two cases:

$$
\begin{gathered}
\theta>2 \delta \\
\text { or } \\
\delta<\theta<2 \delta \text { and } t \leq \frac{n r(\theta-\delta)(\theta+\delta)}{2(2 \delta-\theta)}
\end{gathered}
$$


The bound $\frac{n r(\theta-\delta)(\theta+\delta)}{2(2 \delta-\theta)}$ increases with $n, r$ and $\theta$.

The condition on the total demand $q_{1}+q_{2} \leq n$, taking into account $q^{E O M}$ reads: $(n r \theta(\theta-\delta)$ 4) $t \leq n r(\theta+\delta)$. This last condition is fulfilled if one of the following two conditions is satisfied:

$$
\begin{gathered}
n r \theta(\theta-\delta)-4<0, \\
\text { or } \\
n r \theta(\theta-\delta)-4<0 \text { and } t \leq \frac{n r(\delta+\theta)}{n r \theta(\theta-\delta)-4} .
\end{gathered}
$$

$\frac{n r(\delta+\theta)}{n r \theta(\theta-\delta)-4}$ decreases with $n, r$ and $\theta$, and could decrease or increase with $\delta$.

Furthermore,

$$
\frac{n r(\theta-\delta)(\delta+\theta)}{2(2 \delta-\theta)}>\frac{n r(\delta+\theta)}{n r \theta(\theta-\delta)-4} \text { if and only if } n r<\frac{2}{(\theta-\delta)^{2}}
$$

Mixing conditions (13) and (14) taking into account (15), five possibilities as described below characterize the feasibility of equilibrium $\left(O^{E O M}, \mathrm{D}=0\right)$. The two firms exclusively undertake offensive marketing at the equilibrium if one of the following conditions is satisfied:

$$
\begin{aligned}
& -\theta \geq 2 \delta \text { and } n r \leq \frac{4}{\theta(\theta-\delta)} \\
& -\quad \theta \geq 2 \delta, n r>\frac{4}{\theta(\theta-\delta)} \text { and } t \leq \frac{n r(\delta+\theta)}{n r \theta(\theta-\delta)-4} \\
& -\delta<\theta<2 \delta, n r \leq \frac{4}{\theta(\theta-\delta)} \text { and } t \leq \frac{n r(\theta-\delta)(\delta+\theta)}{2(2 \delta-\theta)} \\
& -\delta<\theta<2 \delta, \frac{4}{\theta(\theta-\delta)}<n r \leq \frac{2}{(\theta-\delta)^{2}} \text { and } t \leq \frac{n r(\theta-\delta)(\delta+\theta)}{2(2 \delta-\theta)} \\
& -\quad \delta<\theta<2 \delta, n r>\frac{2}{(\theta-\delta)^{2}} \text { and } t \leq \frac{n r(\delta+\theta)}{n r \theta(\theta-\delta)-4} .
\end{aligned}
$$




\section{REFERENCES}

Berger, Paul D. and Nada Nasr Bechwati (2001), "The Allocation of Promotion Budget to Maximize Customer Equity," OMEGA, 29(1), 49-61.

Blattberg, Robert C. and John Deighton (1996), "Manage Marketing by the Customer Equity Test," Harvard Business Review, 74(4), 136-144.

Biscaia, Ricardo and Isabel Mota (2013), "Models of Spatial Competition: A Critical Review," Papers in Regional Science, 92(4), 851-871.

Bridges, Eileen and Per V. Freytag (2009), "When Do Firms Invest in Offensive and/or Defensive Marketing?," Journal of Business Research, 62, 745-749

Chan, Tat y., V. Padmanabhan, and P.B. Seetharaman (2007), “An Econometric Model of Location and Pricing in the Gasoline Market," Journal of Marketing Research, XLIV, 622-635.

Chennamaneni, Pavan Rao, Ramarao Desiraju, and Anand Krishnamoorthy (2017), "Advance Sales of Services: Using Direct versus Indirect Channels," Journal of Service Research, 20(2), 135-151.

Chiu, Hung-Chang, Yi-Ching Hsieh, Yu-Chuan Li, and Monie Lee (2005), "Relationship Marketing and Consumer Switching Behavior,” Journal of Business Research, 58 (12), 16811689.

Chisholm, Darlene C. and George Norman (2012), "Spatial Competition and Market Share: An Application to Motion Pictures," Journal of Cultural Economics, 36, 207-225.

Cleeren, Kathleen, Marnik G. Dekimpe, and Frank Verboven (2006), “Competition in Local-Service Sectors," International Journal of Research in Marketing, 23, 357-367.

Davis, Peter (2006), "Spatial Competition in Retail Markets: Movie Theaters," RAND Journal of Economics, 37(4), 964-982. 
Dolega, Les, Michalis Pavlis, and Alex Singleton (2016), "Estimating Attractiveness, Hierarchy and Catchment Area Extents for a National Set of Retail Centre Agglomerations," Journal of Retailing and Consumer Services, 28, 78-90.

Dong, Yan, Yuliang Yao, and Tony Haito Cui (2011), "When Acquisition Spoils Retention: Direct Selling vs. Delegation under CRM,” Management Science, 57(7), 1288-1299.

Durvasula, Srinivas, Steven Lysonski, and Subhash C. Mehta (2000), "Business to Business Marketing: Service Recovery and Customer Satisfaction Issues with Ocean Shipping Lines," European Journal of Marketing, 34(3/4), 433-452.

Erickson, Gary M. (1985), “A Model of Advertising Competition,” Journal of Marketing Research, 22, 297-304.

Erickson, Gary M. (1993), “Offensive and Defensive Marketing: Closed-Loop Duopoly Strategies," Marketing Letters, 4(4), 285-295.

Fornell, Claes and Birger Wernerfelt (1987), "Defensive Marketing Strategy by Customer Complaint Management: A Theoretical Analysis," Journal of Marketing Research, 24, 337-346.

Fruchter, Gila E. and Simon Pierre Sigué (2005), “Transactions vs. Relationships: What Should the Company Emphasize," Journal of Service Research, 8(1), 18-36.

Fruchter, Gila E. and Simon Pierre Sigué (2009), “Social Relationship and Transactional Marketing Policies: Maximizing Customer Lifetime Value," Journal of Optimization Theory and Applications, 142(3), 469-492.

Fruchter, Gila E. and Simon Pierre Sigué (2013), "Dynamic Pricing for Subscription Services," Journal of Economic Dynamics \& Control, 37(11), 2180-2194.

Ho, Katherine and Joy Ishii (2011), "Location and Competition in Retail Banking," International Journal of Industrial Organization, 29, 537-546 
Hotelling, Harold (1929), “ Stability in Competition,” Economic Journal 39, 41-57.

Huff, David L. (1964), “Defining and Estimating a Trading Area," Journal of Marketing, $28,34-38$.

Jarrar, Ramla., Guiomar Martín-Herrán, G., and Georges Zaccour (2004), "Markov Perfect Equilibrium Advertising Strategies of Lanchester Duopoly Model: A Technical Note,” Management Science, 50(7), 995-1000.

Jørgensen, Steffen and Simon Pierre Sigué (2015), "Defensive, Offensive, and Generic Advertising in a Lanchester Model with Market Expansion," Dynamic Games and Applications, $4(5), 523-539$.

Jørgensen, Steffen and Georges Zaccour (2004), Differential Games in Marketing. Boston: Kluwer Academic Publishers.

Karray, Salma. (2013), "Periodicity of Pricing and Marketing Efforts in a Distribution Channel," European Journal of Operational Research, 228(3), 635-647.

Martín-Herrán, Guiomar, Shaun McQuitty and Simon Pierre Sigué (2012), "Offensive versus Defensive Marketing: What is the Optimal Spending Allocation?," International Journal of Research in Marketing, 29, 210-219.

Musalem, Andrés and Yogesh Joshi (2009), "How Much Should you Invest in Each Customer Relationship? A Competitive Strategic Approach," Marketing Science, 28(3), 555-565.

Pfeifer, Phillip E. (2005), "The Optimal Ratio of Acquisition and Retention Costs," Journal of Trageting, Measurement and Analysis for Marketing, 13(2), 179-188.

Reinartz, Werner, Jacquelyn S. Thomas, and V. Kumar (2005), "Balancing Acquisition and Retention Resources to Maximize Customer Profitability," Journal of Marketing, 69(1), 6379. 
Shaffer, Greg and Florian Zettelmeyer (2009), “Comparative Advertising and In-Store Displays," Marketing Science, 28(6), 1144-1156.

Steenkamp, Jan-Benedit E., Vincent R. Nijs, Dominique M. Hassens, Marnick G. Dekimpe (2005), "Competitive Reactions to Advertising and Promotion Attacks," Marketing Science, 24(1), 35-54.

Tsao, Hsiu-Yuan (2013), "Budget Allocation for Customer Acquisition and Retention while Balancing Market Share Growth and Customer Equity," Marketing Letters, 24, 1-11.

Voss, Glenn B. and Zannie Giraud Voss (2008), “Competitive Density and the Customer Acquisition - Retention Trade-Off," Journal of Marketing, 72, 3-18. 
Table 1

$\begin{array}{llllllll} & & \text { Stronger responses } & \text { Identical responses } & \text { Weaker responses } \\ \text { t above } & \text { Cost DM } & \theta \in[0,1] & \theta \in[1,2] & \theta \in[0,1] & \theta \in[1,2] & \theta \in[0,1] & \theta \in[1,2] \\ \text { threshold } & c \in\{0.75,0.9\} & \text { EDM } & \text { EDM } & \text { EDM } & \text { EDM } & \text { EDM } & \text { ODM } \\ \text { (market } & c=0.5 & \text { EDM } & \text { EDM } & \text { EDM } & \text { EDM } & \text { EDM, ODM } \\ \text { power) } & & & & & & \text { ODM } & \text { EOM } \\ & c=0.25 & \text { ODM } & \text { ODM } & & & \text { EOM } \\ \text { t below threshold (no market } & & & & & \text { EOM } \\ \text { power) } & & & & & & \end{array}$

DM: Defensive Marketing.

EDM: Exclusive Defensive Marketing equilibrium.

EOM: Exclusive Offensive Marketing equilibrium.

ODM: Offensive-Defensive Marketing equilibrium. 

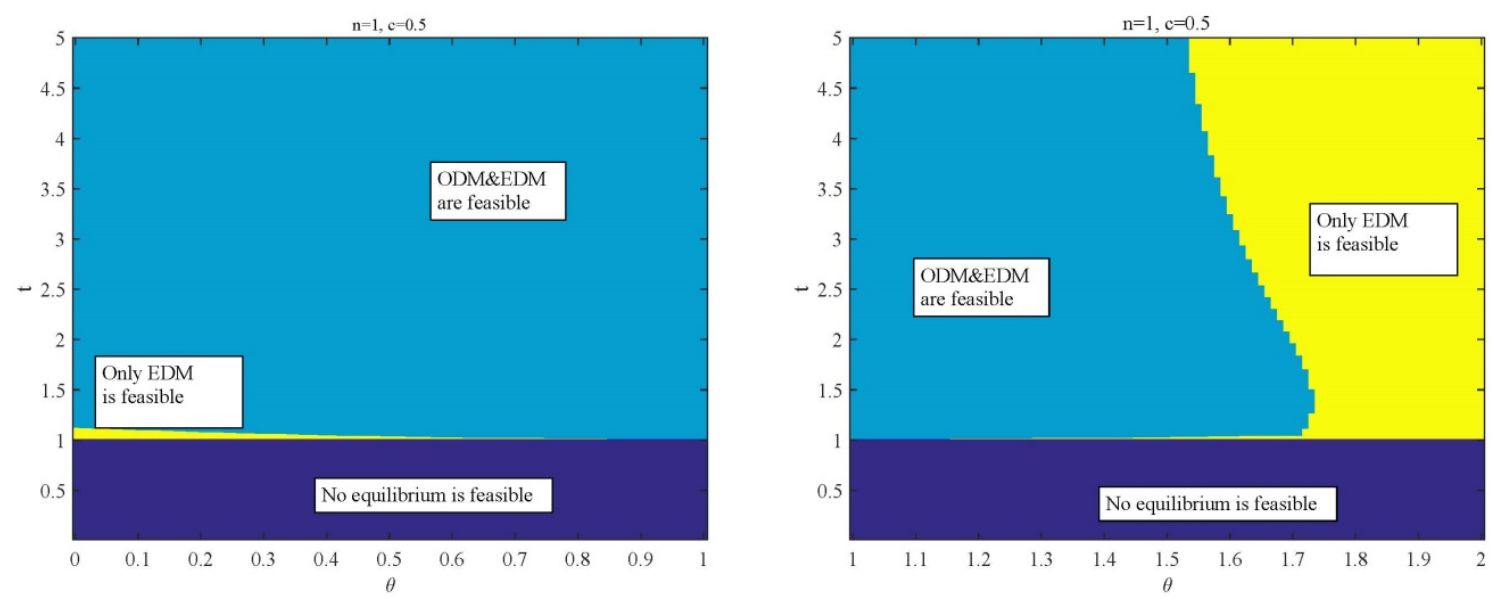

Figure 1: Feasibility scenario $\delta=\theta$. Figure 1a $\theta \in[0,1]$; Figure $1 \mathrm{~b} \theta \in[1,2]$. 


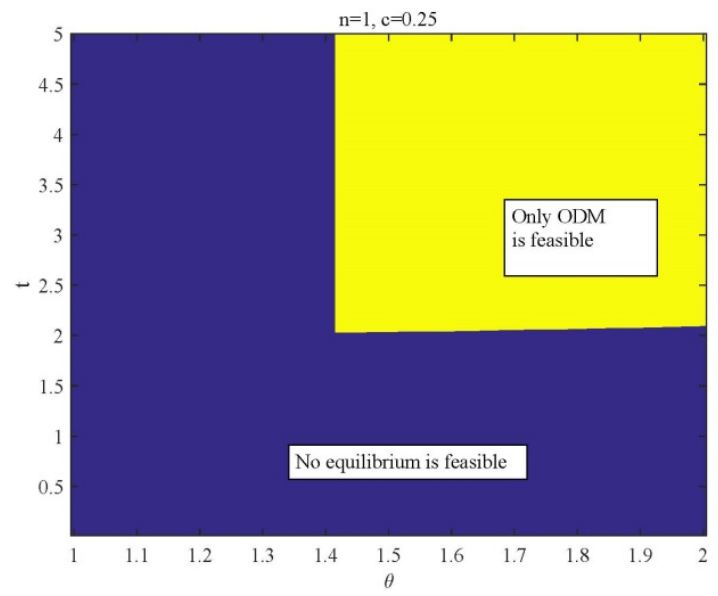

Figure 2: Feasibility scenario $\delta=\theta, \theta \in[1,2]$. 

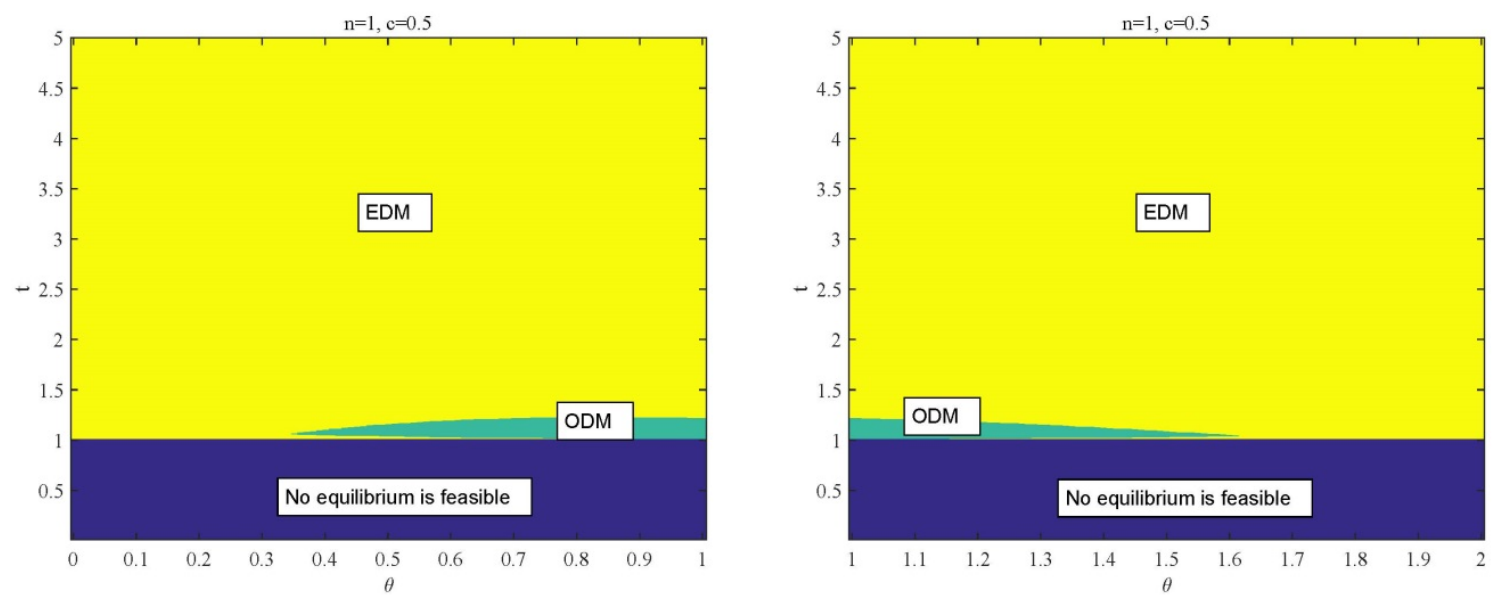

Figure 3: Equilibria scenario $\delta=\theta$. Figure $3 a t \theta \in[0,1]$; Figure $3 b \theta \in[1,2]$. 

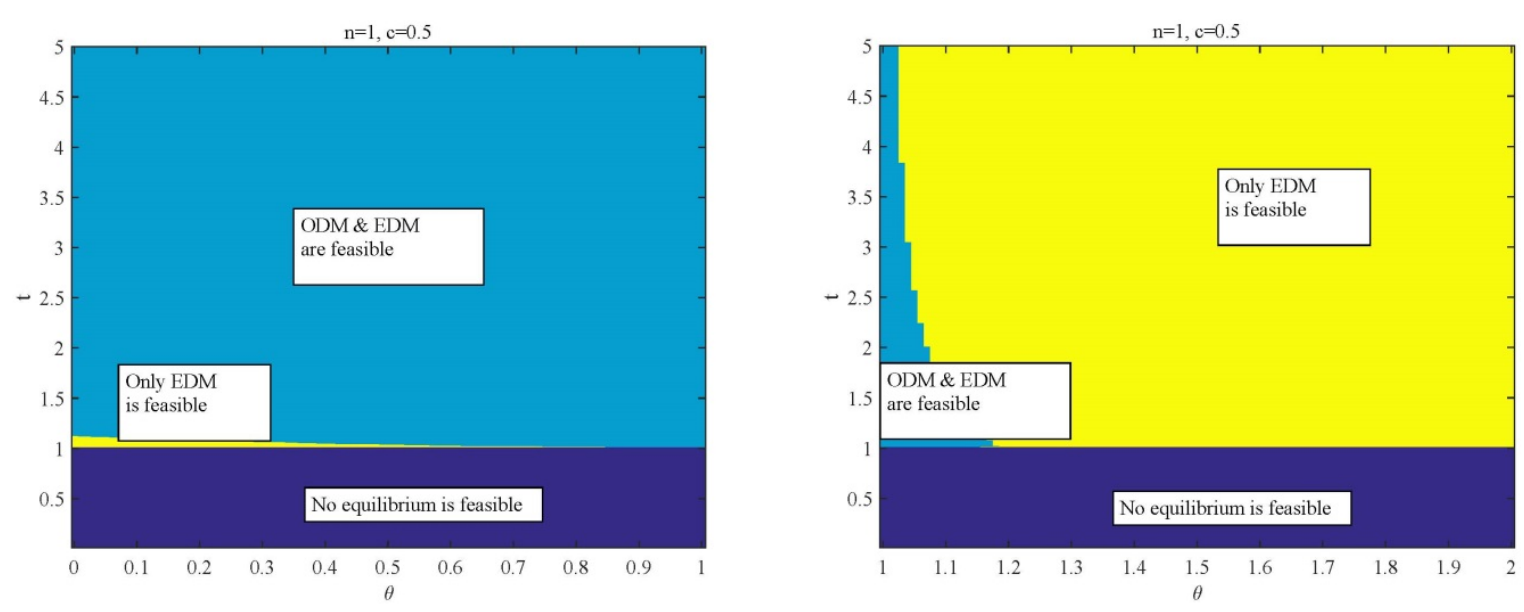

Figure 4: Feasibility scenario $\delta=1.5 \theta$. Figure $4 \mathrm{a} \theta \in[0,1]$; Figure $4 \mathrm{~b} \theta \in[1,2]$. 

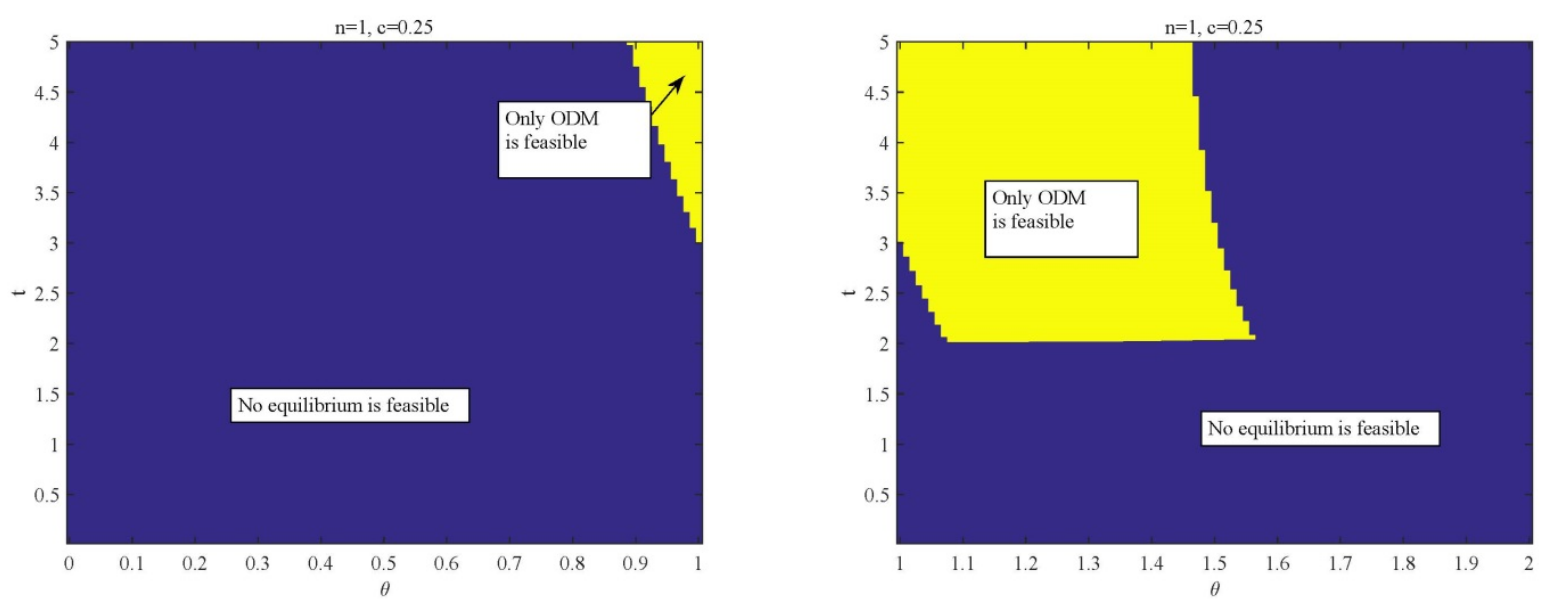

Figure 5: Feasibility scenario $\delta=1.5 \theta$. Figure $5 \mathrm{a} \theta \in[0,1]$; Figure $5 \mathrm{~b} \theta \in[1,2]$. 

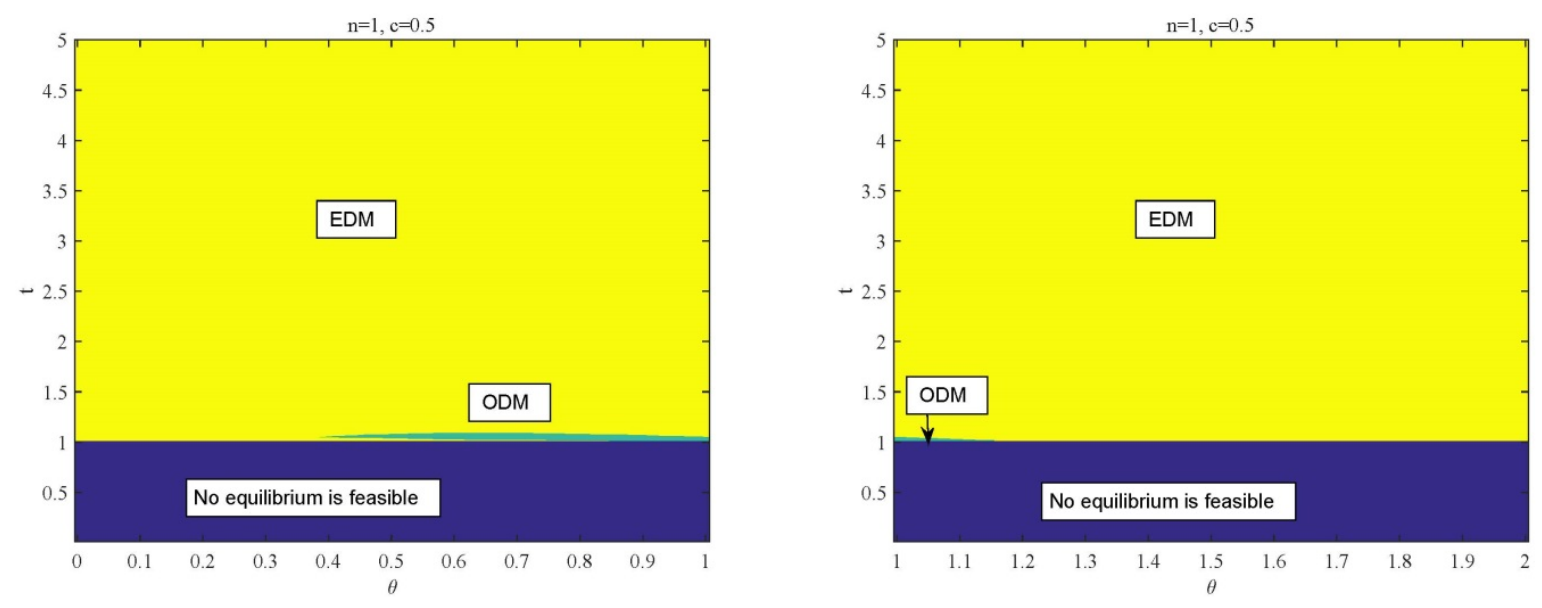

Figure 6: Equilibria scenario $\delta=1.5 \theta$. Figure $6 \mathrm{a} \theta \in[0,1]$; Figure $6 \mathrm{~b} \theta \in[1,2]$. 

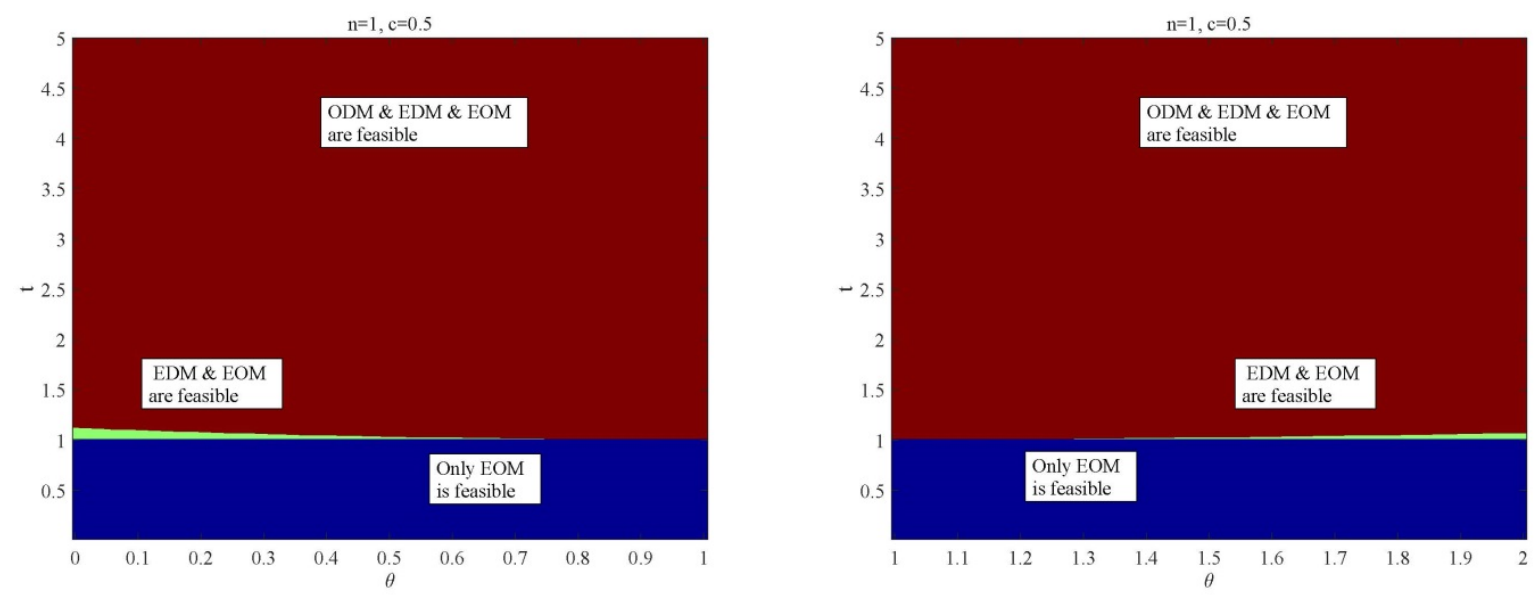

Figure 7: Feasibility scenario $\delta=0.5 \theta$. Figure $7 \mathrm{a} \theta \in[0,1]$; Figure $7 \mathrm{~b} \theta \in[1,2]$. 

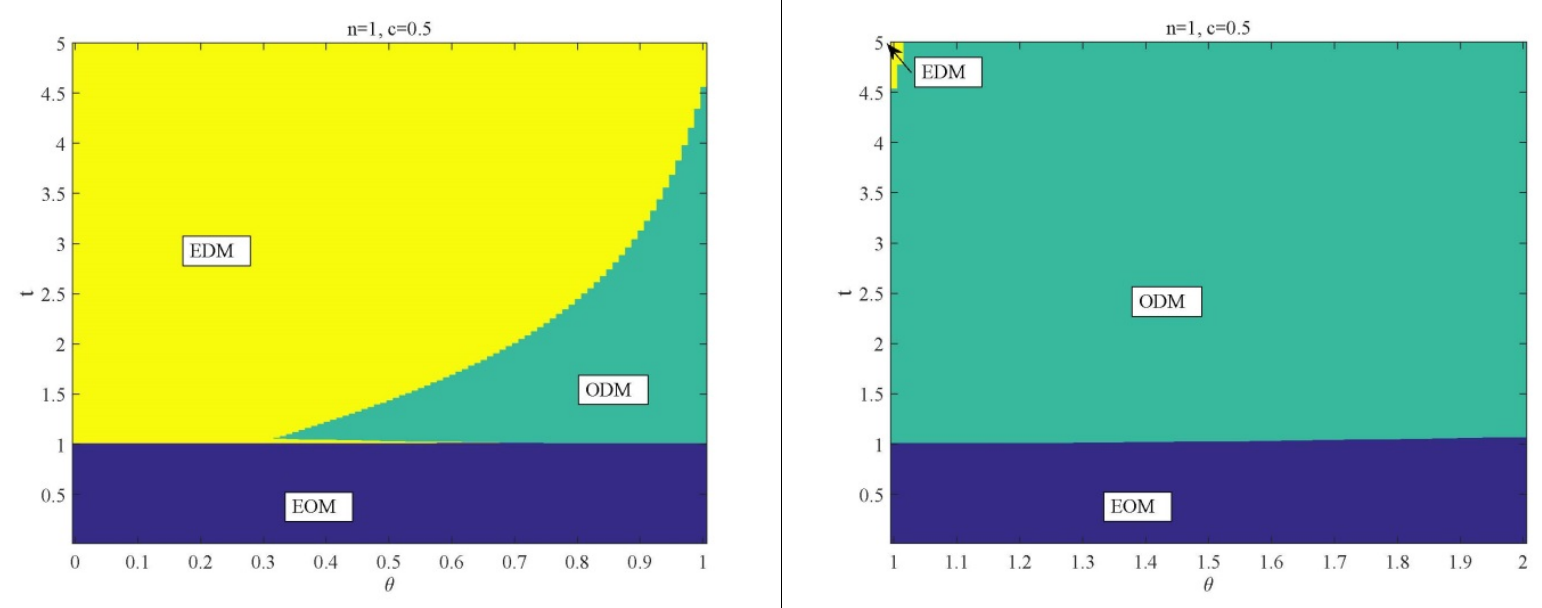

Figure 8: Equilibria scenario $\delta=0.5 \theta$. Figure $8 \mathrm{a} \theta \in[0,1]$; Figure $8 \mathrm{~b} \theta \in[1,2]$. 